European Association for the

Development of Renewable Energies,

Environment and Power Quality (EA4EPQ)
International Conference on Renewable Energies and Power Quality (ICREPQ'11)

Las Palmas de Gran Canaria (Spain), 13th to 15th April, 2011

\title{
PERFORMANCE AND EFFICIENCY OF A BI-FUEL BIO METHANE/GASOLINE VEHICLE
}

\author{
Brenda S. Lemke ${ }^{1}$, Nolan McCann ${ }^{2}$, and Ahmad Pourmovahed, Ph.D ${ }^{3}$ \\ Mechanical Engineering Department \\ Kettering University \\ 1700 W. University Avenue Flint, Michigan, 48504 U.S.A. \\ ${ }^{1}$ Lecturer \\ Phone number: 810-762-9500 ext. 5833, e-mail: blemke@ kettering.edu \\ ${ }^{2}$ Mechanical Engineer \\ Phone number: 989-948-1026, e-mail: nmccann@kettering.edu \\ ${ }^{3}$ Professor \\ Phone number: 810-762-9758, e-mail: apourmov@kettering.edu
}

\begin{abstract}
Compressed natural gas (CNG) vehicles have been utilized in fleet applications in the United States for decades. However, vehicles capable of running on both gasoline and CNG are uncommon, with very few applications intending to use bio methane instead of CNG. This paper discusses the conversion of a production vehicle running on gasoline, $\mathrm{CNG}$, and bio methane, the product of upgraded biogas. The technology used in this application allows the vehicle to switch instantaneously between the liquid and gaseous fuels without affecting drivability. The CNG tank is mounted in the bed of the truck and is plumbed to the engine bay, where the fuel is injected into the engine via natural gas fuel injectors. The vehicle is tested for exhaust gas emissions ( $\mathrm{CO}, \mathrm{CH}_{4}, \mathrm{CO}_{2}, \mathrm{NO}_{\mathrm{x}}$, and $\left.\mathrm{HC}\right)$. This article will present a detailed description of the bi-fuel vehicle, the CNG fuel system, the test procedures followed, the aforementioned test data, analysis of the test results, and a comparison of the results for $\mathrm{CNG}$ and gasoline as fuels.
\end{abstract}

\section{Key Words}

Natural Gas Vehicle, Bi-Fuel, Biogas, Emissions

\section{Introduction}

Kettering University (formerly GMI Engineering \& Management Institute) is a fully cooperative private institution that offers degree programs in engineering, sciences and business. In 2010, Kettering University received a research grant from the United States Department of Energy (DOE) through the Michigan Economic Development Corporation (MEDC) to verify and improve process parameters for the production of biogas at the Flint, Michigan Wastewater Treatment Plant (WWTP) and to determine the feasibility of utilizing biogas in transportation and power generation applications. This project involved the selection and outfitting of a vehicle with a bi-fuel CNG kit. After investigating various vehicles and conversion technologies, a 2009 Chevrolet 2500 HD gasoline truck and a bi-fuel CNG conversion kit were purchased, and the conversion was completed at Kettering University (Figure 1).

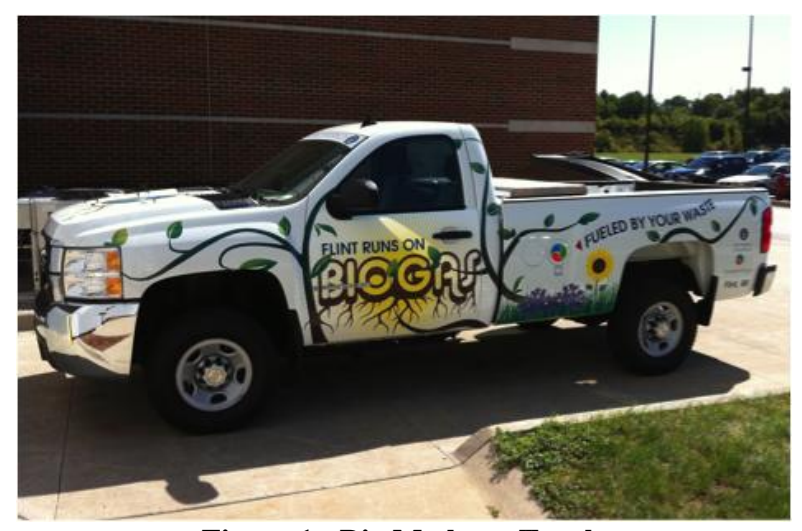

Figure 1 - Bio Methane Truck

While biogas produced through anaerobic digestion at the Flint Wastewater Treatment Plant is indeed a combustible fuel, it must be upgraded to bio methane before it can be used in an internal combustion engine. Biogas is about $62 \%$ methane, $37 \%$ carbon dioxide, and may have small amounts of chemical compounds (specifically hydrogen sulfide) that can be harmful to the metal in an internal combustion engine. Thus, it must be upgraded to bio methane, a fuel that is $95 \%$ (or greater) methane and has a reduced hydrogen sulfide content. The 
bio methane can then be used in place of natural gas in the bi-fuel truck. The only difference between bio methane and natural gas is the source of the methane; otherwise they are chemically interchangeable.

\section{Brief History}

Although internal combustion engines were being developed back into the mid 1800s, natural gas was not considered as a fuel for these engines until the 1930s. After World War II, crude oil demand grew and the use of natural gas faded. The U.S. government was evaluating natural gas as a valid alternative to gasoline for vehicles back in the 1980s. However, U.S. automakers never moved forward with producing natural gas vehicles (NGVs) due to concerns regarding both profitability and demand. Today, NGVs still only represent a fraction of all national vehicles. [1].

Currently, the only offering from an Original Equipment Manufacturer (OEM) in the U.S. for an NGV is the 2010 Honda Civic GX (which represents $0.3 \%$ of all 2010 Hondas sold). However, NGVs are far more prevalent in fleet applications (such as waste trucks, service vans, etc). But, outside of the U.S., NGVs are much more widely used. While the number of $\mathrm{CNG}$ vehicles in North America has remained relatively flat over the previous two decades, significant growth has occurred in the AsiaPacific and Latin American regions, especially in the last ten years [2].

\section{Vehicle Conversion}

Although OEM offerings for NGVs in the U.S. are limited, there are many available options for aftermarket conversion. The majority of these are for trucks intended for government and corporate fleet applications; however there are common passenger car conversion kits available. Without a well-developed infrastructure for NGV fuelling in the U.S., many companies with multiple NGVs opt to install a fuelling station on-site.

Vehicle conversion kits are available for dedicated systems that convert the vehicle to run exclusively on $\mathrm{CNG}$. Conversely, bi-fuel conversion kits require additional fuel and control systems be added along with the factory system. Bi-fuel kits offer the benefit of extending the total vehicle range. The Kettering University bio methane truck, with both the CNG and gasoline tanks full has a range of approximately 730 highway miles (240 miles on CNG and 490 miles on gasoline).

Conversion kits generally range from USD $\$ 7,000$ to $\$ 20,000$, depending on many factors. These include, but are not limited to, emissions certification levels, hardware used in the fuel system, and factory electronics integration and refinement. It is common for conversion kit companies to offer kits downstream of the fuel pressure regulator, leaving the high-pressure lines and tank mounting up to the installer. The cost of the system used on the bio methane truck was approximately (USD) $\$ 4,100$ for the tank, $\$ 7,900$ for the conversion kit, and $\$ 4,000$ for additional installation hardware and tools.

The tank chosen for the bio methane truck is made of a carbon fiber composite. It measures 21 in. x 60 in. and is rated for 3600 psi. The energy content of the fuel when the tank is filled is equivalent to the energy content of 21 gallons of gasoline (see section 8 for further detail). The mounting of the CNG fuel tank in the bed of the truck required metal straps with reinforced steel strips on the underside of the bed. The composite fuel storage tank requires protection from the weather. A cover was fabricated which also allows the bed to be used without worry about damage to the tank (Figure 2).

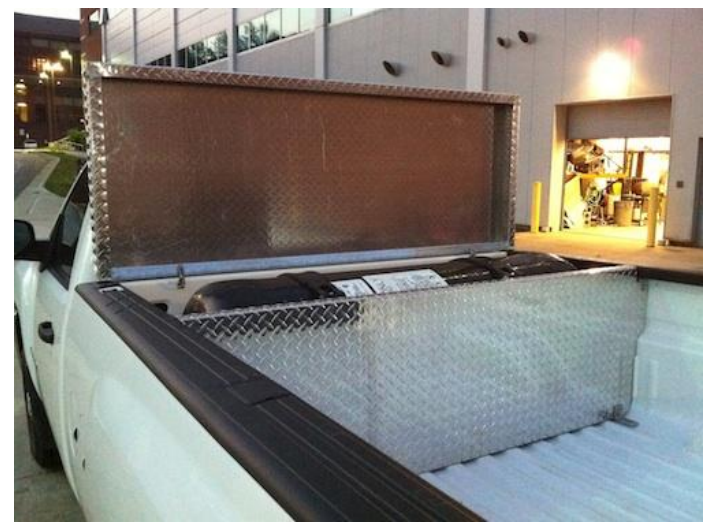

Figure 2 - CNG Tank and Protective Cover

The CNG fuel receptacle and a second fuel door were installed next to the gasoline fuel door for a professional and factory-looking installation. Figure 3 shows both fuel doors.

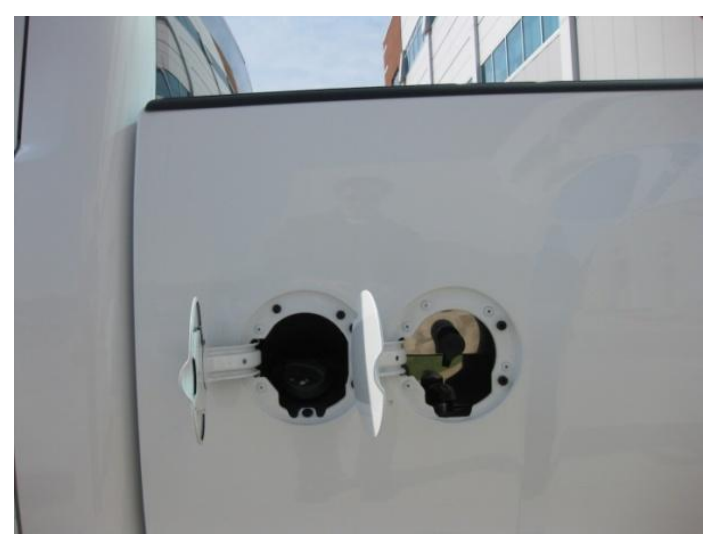

Figure 3 - Dual Fuel Fill Doors

For a short video highlighting the main focal points of the vehicle conversion project, visit the following link:

http://www.kettering.edu/futurestudents/undergraduate/ cng truck video.jsp

\section{Emissions Test Procedure}

The truck was evaluated for tailpipe emissions based on a modified EPA FTP-75 drive cycle (Figure 4). This is the primary cycle used in vehicle emissions certification. 


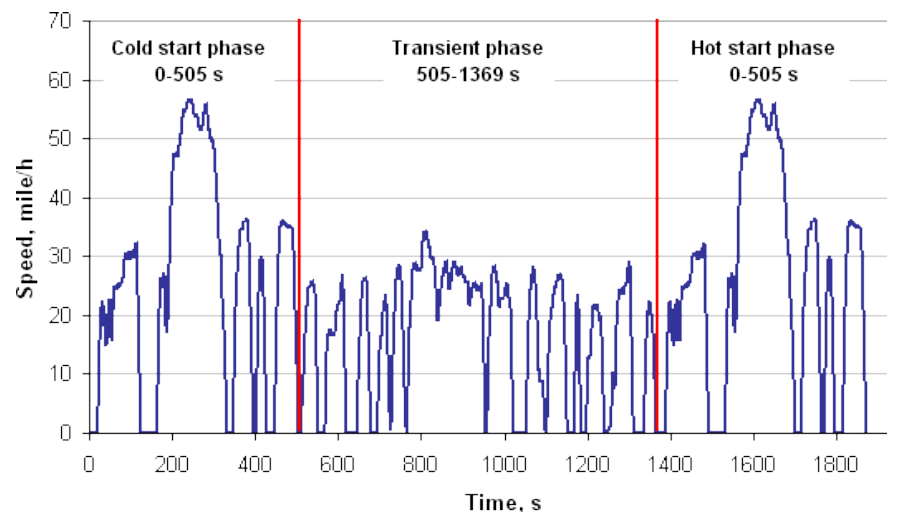

Figure 4 - FTP-75 Drive Cycle [3]

Three distinct phases make up the FTP-75 cycle. The cold start phase (phase 1) represents starting a vehicle and almost instantly driving onto the highway. The transient phase (phase 2) occurs immediately following the cold start phase and consists of low speed driving. At the end of the transient phase, the vehicle is shut off for 10 minutes, restarted, and the hot start phase (phase 3) is then completed. This represents parking and shutting the vehicle off for several minutes, restarting, and then continuing to drive. The hot start phase profile is identical to that of the cold start phase [3]. Loading coefficients derived from vehicle coast down testing were input into the chassis dynamometer to accurately simulate the aerodynamic drag and rolling resistance the vehicle experiences during on-road driving.

The natural gas conversion kit installed on the truck forces the engine to start on gasoline, even when the natural gas is switched on. This prevents old gasoline from remaining in the fuel lines, clogging the gasoline fuel system if it is not used for long periods of time. When the engine is started, the vehicle will run on gasoline until the operating temperature is reached and then it will switch to natural gas. If the engine temperature is already at operating temperature prior to start-up, the vehicle will run for 30 seconds on gasoline prior to switching to natural gas. This required a slight modification to the FTP-75 cycle by not using a true "cold start" to allow the engine to run on $\mathrm{CNG}$ for as much of the test duration as possible. Instead of the test beginning as soon as the vehicle was started, it was left to idle until the engine reached operating temperature and the system switched to CNG as the combusted fuel.

\section{Emissions Data}

Figures 5 through 10 contain exhaust emissions data for $\mathrm{CO}, \mathrm{CH}_{4}, \mathrm{CO}_{2}, \mathrm{NO}_{\mathrm{x}}$, hydrocarbon (HC), and non-methane hydrocarbon (NMHC) levels measured during the testing procedure when running on gasoline and when running on CNG. Additionally, the applicable EPA SULEV (Super Ultra Low Emissions Vehicle) maximum certification level values are included for comparison where appropriate [4]. All pollutant levels were reduced when burning $\mathrm{CNG}$ as compared to gasoline with the exception of methane and total hydrocarbon levels. $\mathrm{CO}$ levels were decreased by $45 \%$, NOX by $54 \%, \mathrm{CO}_{2}$ by $22 \%$, and NMHC by $13 \%$. As compared to gasoline, $\mathrm{CH}_{4}$ and total
HC levels both increased by $0.24 \mathrm{~g} / \mathrm{mile}$ when running on CNG. This is not a significant concern; the slight increase of $\mathrm{CH}_{4}$ output is grossly offset by the $170 \mathrm{~g} / \mathrm{mile}$ reduction in $\mathrm{CO}_{2}$.

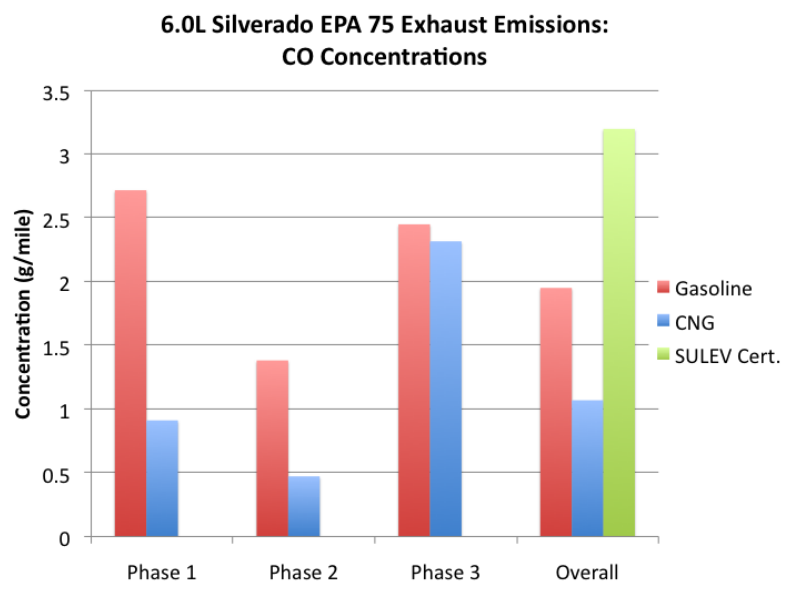

Figure 5 - CO Emissions

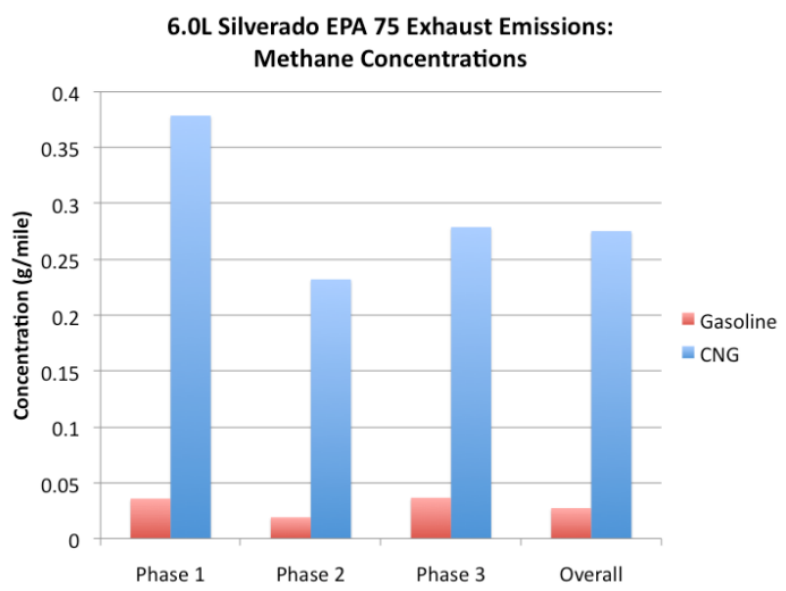

Figure 6 - Methane Concentrations

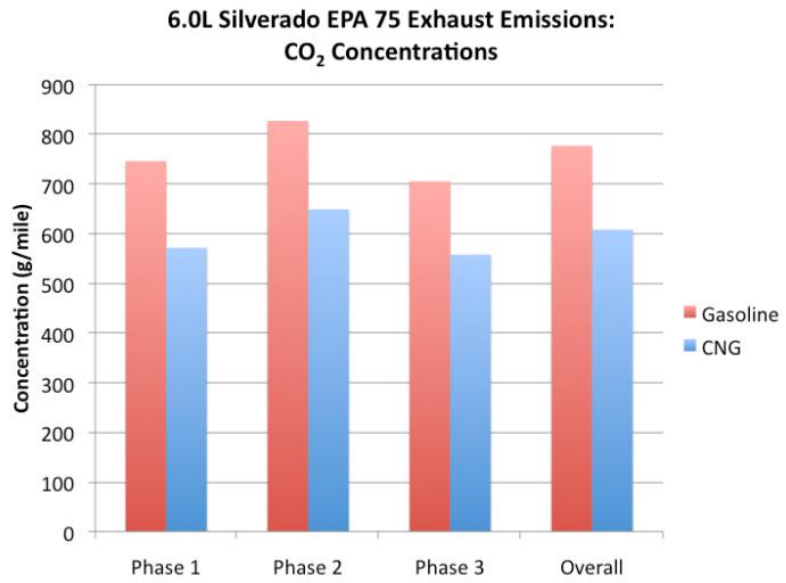

Figure 7 - Carbon Dioxide Concentrations 


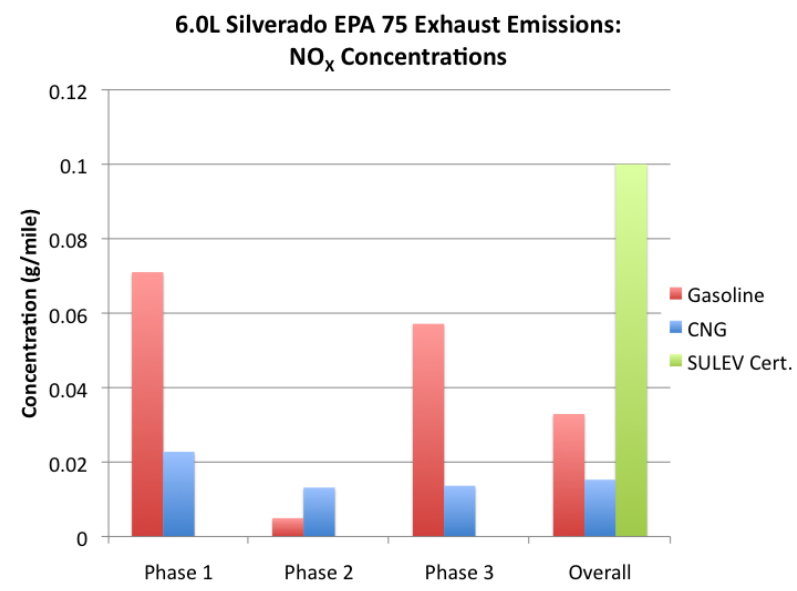

Figure 8 - Nitrogen Oxide Concentrations

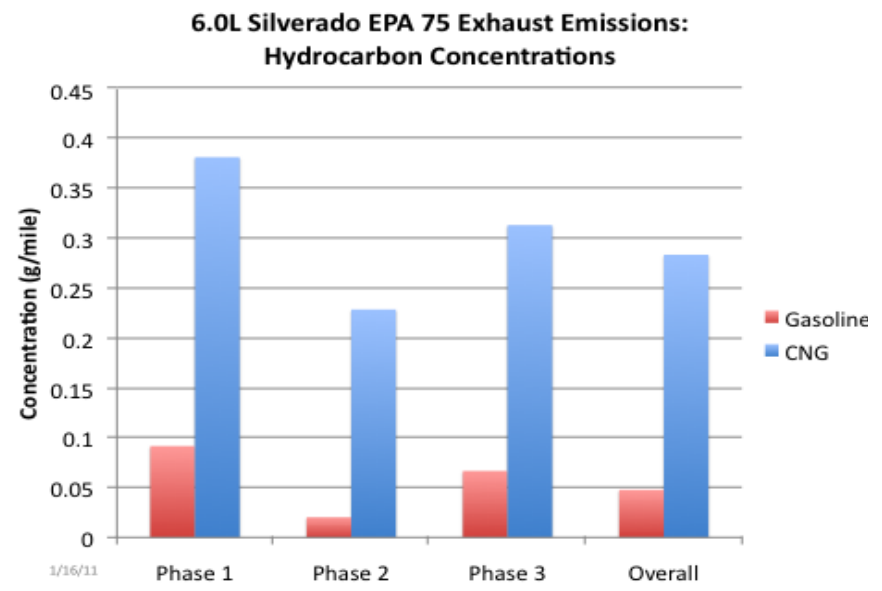

Figure 9 - Hydrocarbon Concentrations

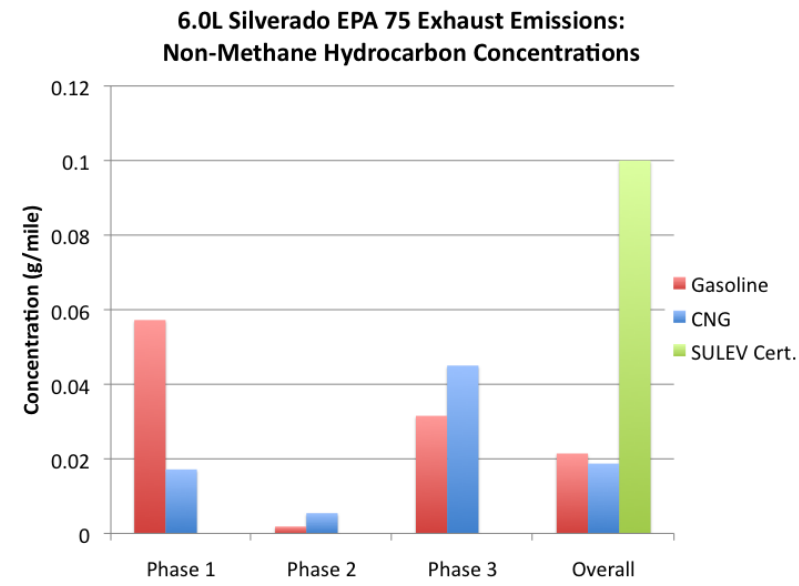

Figure 10 - Non-Methane Hydrocarbon Concentrations

Emissions changes between fuels in the vehicle tested are comparable to those of a natural gas vehicle conversion done by the U.S. Postal Service in 1992 (see Figure 11) [5]. In their conversion, NMHC levels increased by $37 \%$, but $\mathrm{CO}$ and $\mathrm{NO}_{\mathrm{x}}$ levels were reduced by $31 \%$ and $51 \%$, respectively. This vehicle met the ULEV certification standard in 1992 when running on CNG.

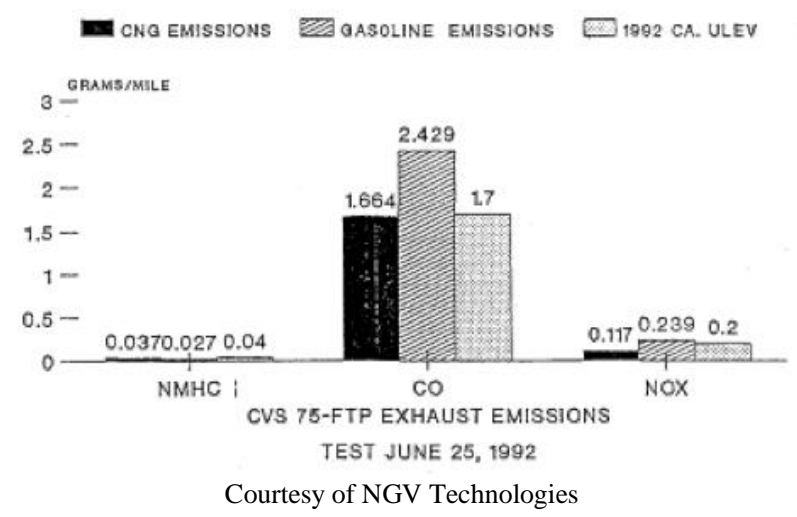

Figure 11 - USPS CNG Conversion Emissions [5]

\section{Fuel Economy}

Acquiring a "city" fuel economy value for natural gas vehicles as it is typically measured on a chassis dynamometer during the FTP-75 drive cycle requires significant modification of the calculations used in producing this number. Specific fuel data (such as $\mathrm{H}: \mathrm{C}$ ratio, density, heating value, etc) are required inputs as the fuel economy is determined based on exhaust $\mathrm{CO}_{2}$. Although indirect, because of the accuracy of the exhaust gas measurement instrumentation, this is a very repeatable method of measurement and far more convenient than attempting to directly meter fuel consumption. The truck averaged 11.4 miles/gallon (MPG) on gasoline and 10.7 miles per gasoline gallon equivalent (MPGGE) on CNG based on the FTP-75 cycle (Figure 12). Based on approximately 1100 miles of actual highway driving, the highway fuel economy average was 14.7 MPGGE on CNG and 14.4 MPG on gasoline.

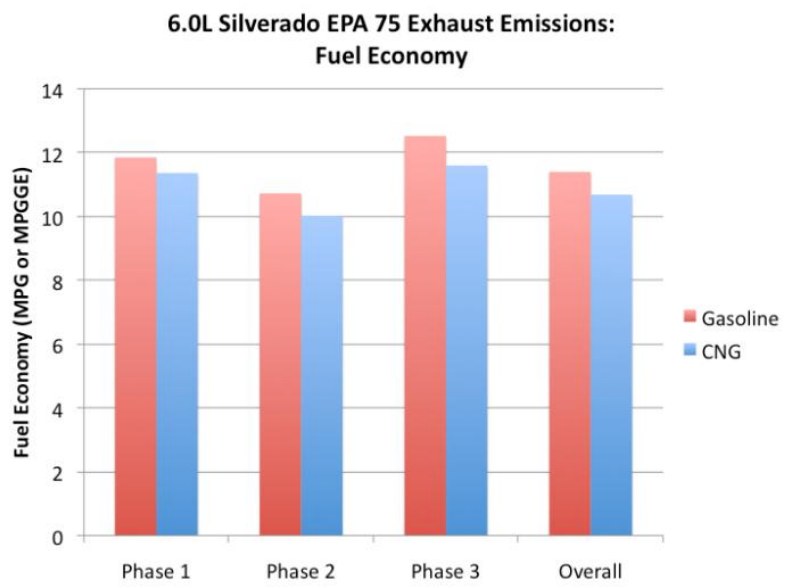

Figure 12 - Fuel Economy from FTP-75 Cycle

\section{Performance Analysis}

Power and torque output were measured on a chassis dynamometer (Figure 13) while running on $\mathrm{CNG}$ and gasoline. Because of natural gas being a gaseous fuel, air is displaced in the higher engine RPM range and torque decreases. This ultimately results in around a $10 \%$ decrease of peak power output. It is noteworthy that rated 
engine power ( 353 horsepower) drops by about $15 \%$ when measured at the rear wheels while running on gasoline. This is due to driveline losses. The torque lines below represent effective engine torque once it has gone through the driveline losses; horsepower is measured directly at the rear wheels, and torque is calculated based on this measurement.

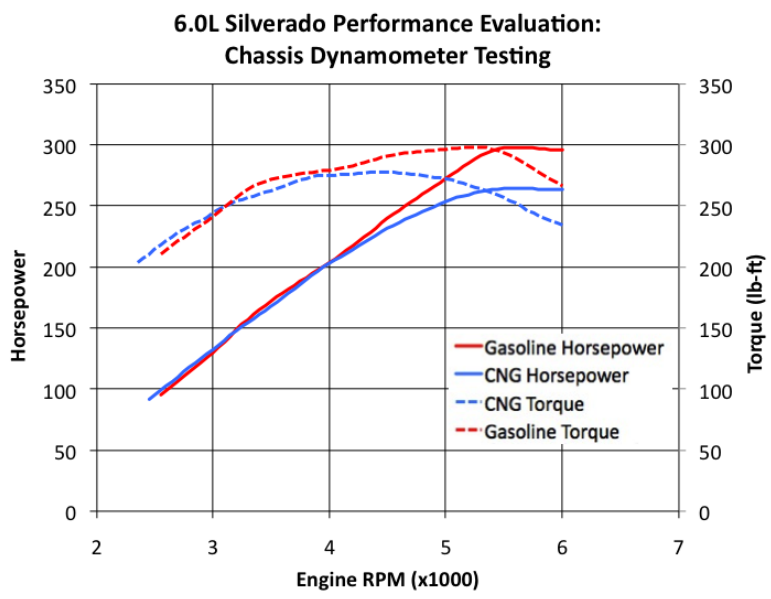

Figure 13 - Chassis Dynamometer Peak Output Plot

Vehicle acceleration was also tested using a Race Technology DL1 data logger/GPS/two axis accelerometer. From a standing start to $60 \mathrm{MPH}$, the truck took roughly 0.7 seconds longer to accelerate while running on CNG as compared to gasoline (Figure 14). This is expected due to the $10 \%$ decrease in power output.

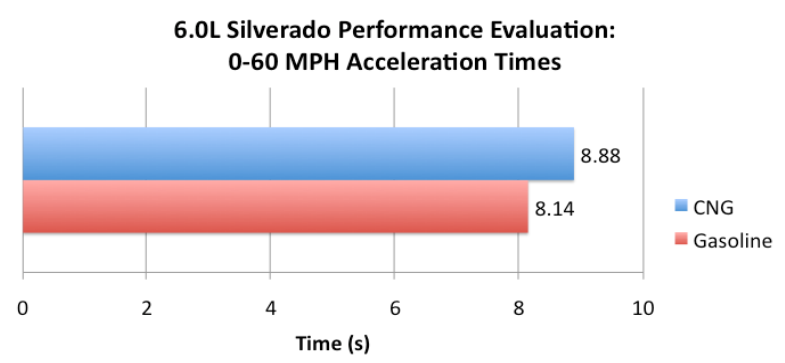

Figure 14 - 0-60 MPH Acceleration Test

\section{CNG Energy Content}

While it is known that 126 cubic feet of CNG at STP contains the same amount of energy as 1 gallon of gasoline (approximately 115,000 BTU) [6], estimating the number of gasoline gallon equivalents (GGEs) in the CNG tank involves more than simply reading the pressure gauge after a fill-up. Because methane is not an ideal gas, it must be treated as having a compressibility factor. Additionally, the gas temperature rise during fill-up results in a pressure increase, causing an error in energy content based on pressure alone.
The following formula is used to calculate the temperature rise when the CNG tank is filled [7]:

$$
T_{2}=\frac{p_{2} \cdot c_{P} \cdot T_{i n}}{c_{v} \cdot\left(p_{2}-p_{1}\right)+\left(p_{1} \cdot c_{p} \cdot T_{i n} / T_{1}\right)}
$$

Where

$\mathrm{T}_{2}=$ Final Gas Temperature

$\mathrm{T}_{1}=$ Initial Gas Temperature

$\mathrm{T}_{\text {in }}=$ Inlet (Fill) Gas Temperature

$\mathrm{P}_{1}=$ Initial Tank Pressure

$\mathrm{P}_{2}=$ Final Tank Pressure

$\mathrm{C}_{\mathrm{p}}=$ Heat capacity at constant pressure of methane $=$ $0.035 \mathrm{~kJ} /\left(\mathrm{mol} \bullet^{\circ} \mathrm{K}\right)$

$\mathrm{C}_{\mathrm{v}}=$ Heat capacity at constant volume of methane = $0.027 \mathrm{~kJ} /\left(\mathrm{mol} \bullet{ }^{\circ} \mathrm{K}\right)$

This formula is used to generate a chart used for determining the final gas temperature for a range of initial tank pressures and initial gas temperatures (see Figure 15.) Because this formula is applicable to ideal gases and neglects the compressibility factor, there will be an anticipated margin of error.

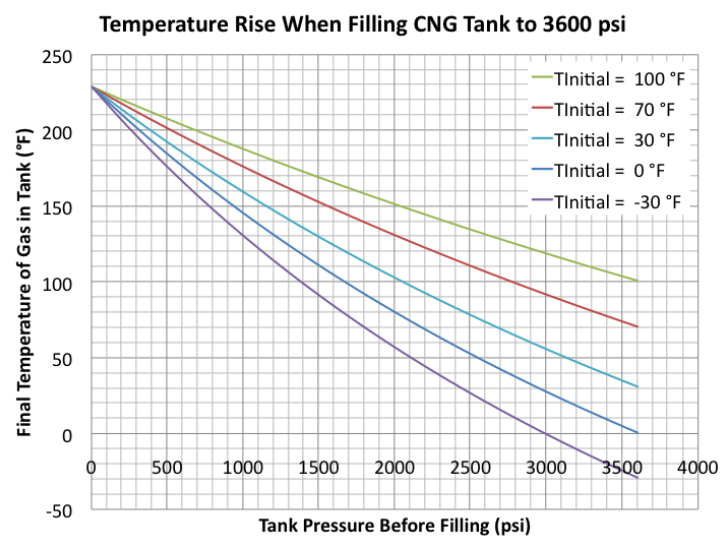

Figure 15 - Temperature Rise from Filling with CNG

Once the gas temperature immediately after being filled has been found, the tank pressure can be used to find the number of GGEs in the tank. Figure 16 has been generated using basic thermodynamics, a compressibility chart, fuel characteristic values, and the CNG tank volume. The graph would be a single line strictly based on the tank pressure, volume, and heating value of $\mathrm{CNG}$ if the fuel compressed linearly and was not affected by the temperature. However, because this is not true, multiple curves are required to convert the tank pressure gauge reading into the number of GGEs. This is accomplished by also factoring in the gas temperature rise as a result of filling the tank and the compressibility of the gas. The increasing nonlinearity of the curves as the temperature drops is due to the increasing compressibility of the methane. 


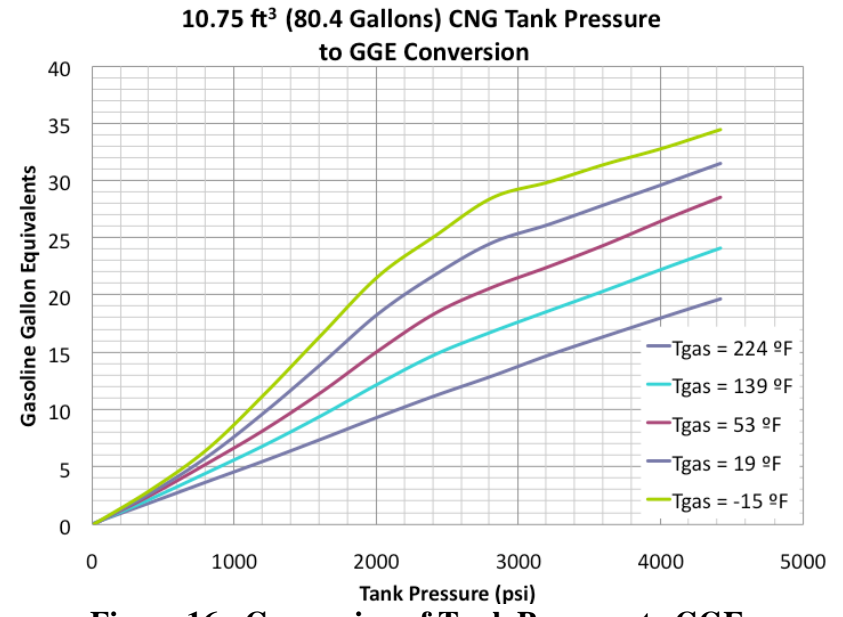

Figure 16 - Conversion of Tank Pressure to GGE

\section{Conclusions}

Kettering University has acquired much new knowledge following the completion of the bi-fuel conversion on the 2009 Chevrolet Silverado truck. At first glance, it's quite difficult to see why natural gas vehicles have not gained momentum and popularity in years past and why OEMs have not brought more CNG-ready vehicles to market. There are some performance losses which are not insignificant, especially in an age where marginal gains in power output are paramount to manufacturers. Yet, from an end user standpoint, a bit of performance and fuel economy loss are willingly absorbed when the fuel cost is significantly lower and the pollutant output greatly reduced.

Unfortunately, the large initial cost and poor refueling infrastructure tend to deter individuals from converting to natural gas. Even with cost savings due to reduced fuel prices, the return on investment where the conversion results in a net gain can be longer than the number of miles most individuals keep a vehicle. It ultimately depends on market conditions and fuel costs, making the choice a bit of a risk in terms of cost. However, CNG conversion systems remain very viable alternatives to gasoline vehicles for government and corporate fleet applications where vehicles are driven frequently and are returned to a central location daily for refueling.

Subjectively, this project has been very successful. Except for a few difficulties during the emissions evaluation, the project went quite smoothly and resulted in a reliable vehicle and a quality conversion.

Additionally, the aim of the vehicle conversion process was to allow Kettering University to be a knowledge center to support local municipalities should they opt for $\mathrm{CNG}$ vehicle conversion for fleet vehicles. After the completion of this project, the University is comfortably prepared to assist in these areas. When the Flint WWTP is capable of producing a sufficient quantity of bio methane, the performance and effects on engine wear with this new fuel will be evaluated.
The vehicle will continue to be used both for utility and demonstration, from the classroom to conferences to car shows (Figure 17).

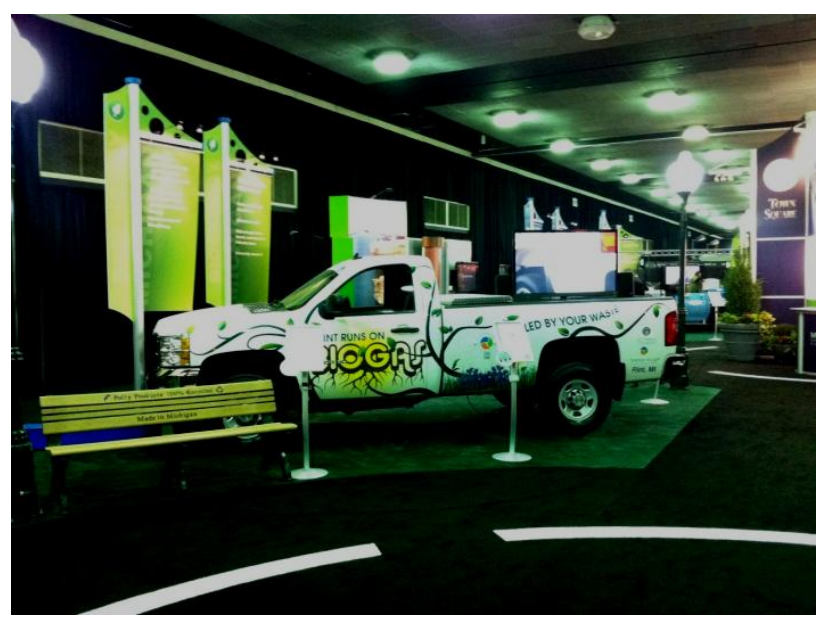

Figure 17 - Bio Methane Truck at 2011 North American International Auto Show, Detroit, Michigan

\section{Acknowledgements}

This research project was funded by the Biogas Center of Energy Excellence grant from the United States Department of Energy (DOE) through the Michigan Economic Development Corporation (MEDC). The authors are also grateful to Swedish Biogas International and the City of Flint, Michigan for their support.

\section{References}

[1] History of Natural Gas Vehicles, (2008), Retrieved January 18, 2011, http://www.randomhistory.com/2008/09/08_ngv.html. [2] Natural Gas Vehicle Statistics, (2011), Retrieved January 18, 2011, http://www.iangv.org/toolsresources/statistics.html.

[3] Drive Cycles, (2010), Retrieved January 18, 2011 http://www.daham.org/basil/leedswww/emissions/drivec ycles.htm.

[4] Cars and Light Trucks - US EPA, (2010), Retrieved January 18, 2011, http://www.epa.gov/OMS/ld-hwy.htm. [5] Clean Vehicle Education Foundation, (2010) Retrieved January 18, 2011 www.cleanvehicle.org. [6] Methane, CH4, Physical Properties, (2009), Retrieved January 18, 2011, http://encyclopedia.airliquide.com Encyclopedia.asp?GasID=41.

[7] Huang, Francis, Engineering Thermodynamics. 2nd ed, Macmillan Publishing Company, New York (1988), pp. 351-353. 